\title{
Epidemiological, clinical, prognostic and therapeutic aspects of twin delivery in two referral maternity units in Dakar (Senegal)
}

\author{
Omar Gassama*, Magatte Mbaye, Aminata Niass, Diodio Boye, Babacar Biaye, \\ Assatou Mbodj, Astou Niassy Colly Diallo, Marie Edouard Faye Dieme, \\ Alassane Diouf, Jean Charles Moreau
}

Obstetrics Clinic and Gynecology, Teaching Hospital, Aristide Le Dantec, Cheikh Anta Diop University, Dakar, Senegal

Received: 03 November 2017

Accepted: 02 December 2017

*Correspondence:

Dr. Omar Gassama,

E-mail: ogasse79@yahoo.fr

Copyright: (c) the author(s), publisher and licensee Medip Academy. This is an open-access article distributed under the terms of the Creative Commons Attribution Non-Commercial License, which permits unrestricted non-commercial use, distribution, and reproduction in any medium, provided the original work is properly cited.

\section{ABSTRACT}

Background: Twin pregnancy is the simultaneous development of two embryos and then two fetuses in the uterine cavity. Objective of present study was to assess the epidemiological, clinical, prognostic and therapeutic aspects of twin delivery in two referral maternity units in Dakar.

Methods: A descriptive and analytical retrospective bi-centric study of all cases of twin deliveries recorded in two referral center in Dakar was conducted during the period January $1^{\text {st }}, 2005$-December $31^{\text {st }}$, 2015, i.e. an 11-year period. It concerned 619 pregnant women who gave birth to twins in these two referral medical structures. The epidemiological parameters, clinical, prognostic and therapeutic aspects of twin childbirth were studied. The data were entered and analysed using Epi info version 3.5.3.

Results: The twinning prevalence was $1.11 \%$. The majority of our parturient women (506 or $81.7 \%$ of the cases) came from the Dakar suburbs. The average age of the parturient women was 28 years and the gestity age 3.1 . Pregnancy was well monitored for $98.5 \%$ of the parturient women with an average number of prenatal consultations of 3.6. The first prenatal consultation was performed in $52 \%$ of cases in the first quarter. In more than one third of cases $(234$ or $37.8 \%)$, the diagnosis was made in the third quarter of pregnancy. 113 cases $(18.2 \%)$ of premature rupture of membranes, 10 cases $(1.61 \%)$ of threat of premature delivery and 7 cases $(11.13 \%)$ of placenta previa were registered. During labour, the diagnosis was made by clinical examination in $32.2 \%$ of cases. Bichorial biamniotic twin pregnancy was the most frequent anatomical type (62.6\%). On admission, the first twin (T1) was in cephalic presentation in $56.7 \%$, in breech presentation in $15.2 \%$; The second twin (T2) was in breech presentation in $21.1 \%$ of the cases. Caesarean section was related to the first twin in 50.6\% and the second twin in $53.8 \%$ of the cases. Caesarean section was performed in $50.6 \%$ for the first twin and in 53.8\% for the second twin. The mean time interval between the delivery of $\mathrm{T} 1$ and that of $\mathrm{T} 2$ was $17.4 \mathrm{~min}$. Low birth weight was more frequent for the second twin $(54.3 \%)$. The stillbirth rate was 48.26 per thousand. Maternal complications were dominated by renal-vascular syndromes $(4.2 \%)$, haemorrhagic causes $(1.86 \%)$, perineal lesions $(1.6 \%)$ and uterine rupture $(0.97 \%)$. Postpartum haemorrhage was observed in 8 cases $(1.29 \%)$. Maternal mortality was nil

Conclusions: Twin delivery poses varying difficulties due to the complexity of obstetrical mechanics and the frequency of dystocic presentations. Despite improved maternal prognosis, in recent years, perinatal mortality and morbidity, still high, remain a constant concern.

Keywords: Maternal prognosis, Prematurity, Premature rupture of membranes, Twin delivery 


\section{INTRODUCTION}

Twin pregnancy is the simultaneous development of two embryos and then two fetuses in the uterine cavity. The management of twin pregnancy and childbirth is well codified in developed countries in contrast to developed countries. Twin pregnancy is of particular interest in our work environment because of its high frequency in black communities, the difficulties encountered in its diagnosis and in the pregnant women follow-up. ${ }^{1}$

Twin delivery has a number of characteristics that are all likely to affect the course of labour and the condition of foetuses at birth with a high rate of maternal and foetal complications. It thus imposes the presence of an experienced team comprising competent midwives, obstetrician, anaesthetist and neonatologist. ${ }^{2,3}$ The objective of this work was to study the epidemiological, clinical, prognostic, diagnostic and therapeutic aspects in order to draw up an inventory on twin deliveries in two referral maternity units in Dakar.

\section{METHODS}

A bi-centric, retrospective, descriptive and analytical study was carried out in the maternity units of Philippe Maguilen Senghor and Nabil Choucair health centres located in the semi-urban Dakar area. This study was carried out during the period January 2005-December 2015 , i.e. a duration of 11 years.

\section{Inclusion criteria}

In present study, any parturient woman with a twin pregnancy whose term was greater than or equal to 22 weeks of amenorrhea (WA) and who had given birth in one of the two above-mentioned maternity units was included. All those with scarred uterus and twin pregnancy with a term of less than 22 WA were excluded.

Parameters for each patient were studied, namely:

- $\quad$ socio-epidemiological: age, ethnicity, marital status, personal background (gesture, parity) and family background (concept of twinning);

- clinical-paraclinical: intergenegic interval, method of admission, fundal height, term, number of prenatal consultations, labour;

- therapeutics: delivery route, delivery progress, prevention and management of delivery haemorrhage and obstetric manoevers.

For the foetus, the parameters studied were the Apgar score, height, weight, sex, type of twinning, search for malformations and traumas.

The data collected were analysed using Epi info software version 3.5.3.

\section{RESULTS}

\section{Frequency}

During the study period, 619 cases of twin deliveries out of a total number of deliveries of 55557 were compiled, representing an overall frequency of $1.11 \%$, distributed between the Philippe Maguilen Senghor health center $(1.5 \%)$ and the Nabil Choucair health center $(0.86 \%)$. Table 1 shows the distribution of parturient women by place of delivery.

Table 1: Distribution of parturient women by the number of PNCs.

\begin{tabular}{|ll|}
\hline PNC & Number $(\%)$ \\
\hline 0 & $9(1.5 \%)$ \\
\hline 1 & $22(3.6 \%)$ \\
\hline 2 & $53(8.6 \%)$ \\
\hline 3 & $164(26.5 \%)$ \\
\hline$\geq 4$ & $356(57.5 \%)$ \\
\hline NP & $15(2.4 \%)$ \\
\hline Total & $619(100 \%)$ \\
\hline
\end{tabular}

\section{Epidemiological characteristics}

The majority of the parturient women, $81.7 \%$, lived in the suburbs as shown in Figure 1.

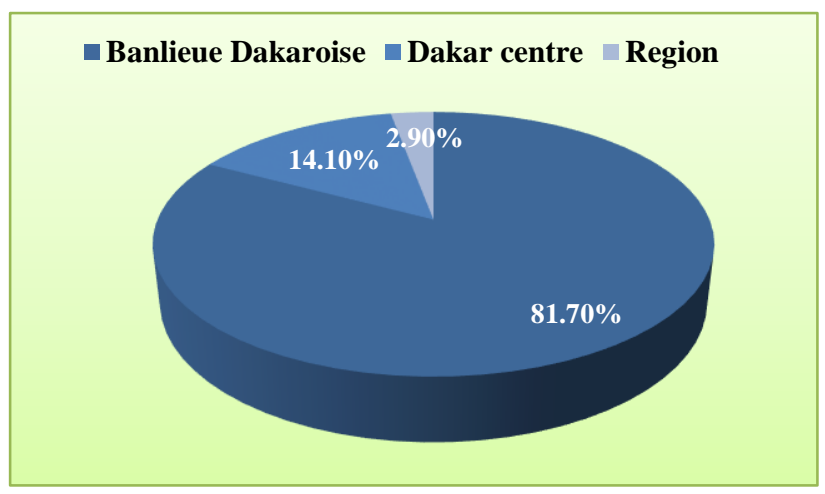

Figure 1: Distribution of women by geographical origin.

The average age of the parturient women was 28 years with extremes; ie 2 patients aged 15 and 46 years, respectively. More than half of the patients $(56.3 \%)$ belonged to the age group of 20-30 years. The average gestity was 3.1 with extremes of 1 and 12 pregnancies. The majority of patients (213 cases or $34.4 \%$ ) were large multigravida.

The average parity was 2.5 with extremes of 1 nulliparous and 1 eleventh parous. Pauciparous accounted for $26.8 \%$ while large multiparous, multiparous, nulliparous and primiparous women accounted for $25.8 \%, 16 \%, 15.8 \%$ and $13.7 \%$, respectively.

\section{Clinical and paraclinical aspects}




\section{Prenatal monitoring}

Pregnancy was monitored for the majority of our parturient women $(98.5 \%)$ with an average number of 3.6 prenatal consultations; the first prenatal consultation was conducted in $52 \%$ in the first quarter, $47 \%$ in the 2 nd quarter and $1 \%$ in the third quarter (Table 1 ).

\section{Diagnostic and therapeutic aspects}

The Twinning diagnosis was made during an ultrasound scan in $78.7 \%$ of cases; this ultrasound diagnosis was performed in $38 \%$ cases in the third quarter, $33 \%$ in the second quarter and $19 \%$ in the first quarter of pregnancy. During labour, the diagnosis was made at the end of the clinical examination in 200 parturient women (32.2\%).

Table 2: Distribution of parturient women by indication of caesarean sections.

\begin{tabular}{|ll|}
\hline Indications of caesarean section & n $(\%)$ \\
\hline Maternal indications & \\
\hline $\begin{array}{l}\text { Premature rupture of membranes } \\
\text { (PRM*) }\end{array}$ & $40(40.82 \%)$ \\
\hline $\begin{array}{l}\text { Mechanical dystocia (BL*, BTR*, } \\
\text { BGR*, lack of commitment) }\end{array}$ & $26(26.53 \%)$ \\
\hline Renal vascular syndrom & $23(23.45 \%)$ \\
\hline Dynamic dystocia (DK) & $5(5.1 \%)$ \\
\hline uterine rupture (UR) & $1(1)$ \\
\hline Precious pregnancy & $1(1.02 \%)$ \\
\hline Loaded background & $1(1.02 \%)$ \\
\hline Vaginal diaphragm & $1(1.02 \%)$ \\
\hline Nursing indications & $1(1.02 \%)$ \\
\hline Sub total & $98(100 \%)$ \\
\hline Foto-adnexal indications of T1 & $124(62.3 \%)$ \\
\hline Breech presentation & $41(20.6 \%)$ \\
\hline Acute fœtal distress & $20(10.1 \%)$ \\
\hline Umbilical cord prolapse & $11(5.5 \%)$ \\
\hline Transverse presentation & $3(1.5 \%)$ \\
\hline Presentation of neglected shoulder & $199(100 \%)$ \\
\hline Sub total & \\
\hline Mixed indications & $5(31.25 \%)$ \\
\hline Dynamic Dystocia (DD) + AFD * & $4(25 \%)$ \\
\hline Blocked route (BR) + SFA & $3(18.75 \%)$ \\
\hline T1 in transversal presentation + PRM & $2(12.5 \%)$ \\
\hline RPH* living child & $2(12.5 \%)$ \\
\hline DD + PRM & $313(100 \%)$ \\
\hline Sub total & RPH*: Retro- \\
\hline Total & \\
\hline PRM*: Premature rupture of membranes, \\
placental haematoma, DD*: Dynamic dystocia, BL*: Limit \\
basin NP: Narrowed pelvis, NP: Narrowed pelvis TNP: \\
$\begin{array}{l}\text { Transversely narrowed pelvis, UR*: Uterine rupture, BR: } \\
\text { Blocked route, AFD: Acute foetal distress }\end{array}$ \\
\hline
\end{tabular}

On admission, the first twin was in cephalic presentation in $56.7 \%$ and in breech presentation in $15.2 \%$ of cases; the second twin was in breech presentation in $21.1 \%$. The predominant delivery route was caesarean section, which was reported in $50.6 \%$ of cases and with the second twin in $53.8 \%$ of cases. The indications were dominated by foeto-adnexal causes in $45.79 \%$ of cases as reported in Table 2.

Deliveries involved obstetric manoeuvres for a major breech extraction in $0.05 \%$ of cases. The average time interval between $\mathrm{T} 1$ and $\mathrm{T} 2$ birth was $17.4 \mathrm{~min}$ with extremes of 02 minutes and $248 \mathrm{~min}$. The average birth weight for the first twin was 2331 grams. Low birth weight was observed in the first twin in $49.3 \%$ of cases. The average birth weight of the second twin was 2245 grams. Low birth weight was observed in the second twin in $54.3 \%$ of cases.

\section{Prognostic aspects}

\section{Maternal prognostic}

Maternal complications were dominated by haemorrhages $(1.8 \%)$, perineal lesions $(1.6 \%)$ and uterine rupture $(1 \%)$. Delivery haemorrhage was observed in 8 cases or $1.3 \%$ including 2 after delivery at home. Maternal mortality was zero.

Table 3: Pregnancy term and Apgar score for the first twin.

\begin{tabular}{|llllll|}
\hline $\begin{array}{l}\text { Apgar score } \\
\text { for T1 } \\
\text { Pregnancy } \\
\text { term }\end{array}$ & $\begin{array}{l}\leq 7 \\
\mathrm{n}(\%)\end{array}$ & $\begin{array}{l}>7 \\
\mathrm{n}(\%)\end{array}$ & Total & $\mathrm{p}$ & OR \\
\hline$<37$ WA & $\begin{array}{l}25 \\
(17 \%)\end{array}$ & $\begin{array}{l}122 \\
(83 \%)\end{array}$ & 147 & 0.006 & 2.10 \\
\hline \multirow{2}{*}{37 WA } & $\begin{array}{l}37 \\
(8 \%)\end{array}$ & $\begin{array}{l}379 \\
(91 \%)\end{array}$ & 416 & & \\
\hline
\end{tabular}

\section{Neonatal prognostic}

New-borns (first and second twins) were alive in $91.9 \%$ of cases with an Apgar score in the first minute greater than 7/10. The Apgar score was less than 7 in $8.1 \%$ of cases for the first twin and $8.6 \%$ of cases for the second and stillbirth stood at $45 \%$; the death of one of the foetuses was observed in $4.5 \%$ of cases. Perinatal morbidity was mainly due to neonatal infection (37 cases, or 6\%) (Table 4).

Table 4: Pregnancy term and Apgar score for the second twin.

\begin{tabular}{|llllll|}
\hline $\begin{array}{l}\text { Apgar score } \\
\text { for T2 } \\
\text { Pregnancy } \\
\text { term }\end{array}$ & $\begin{array}{l}\leq 7 \\
\mathrm{n}(\%)\end{array}$ & $\begin{array}{l}>7 \\
\mathrm{n}(\%)\end{array}$ & Total & $\mathrm{p}$ & OR \\
\hline 37 WA & $\begin{array}{l}29 \\
(20 \%)\end{array}$ & $\begin{array}{l}118 \\
(80 \%)\end{array}$ & 147 & 0.000 & 2.62 \\
\hline 37 WA & $\begin{array}{l}36 \\
(9 \%)\end{array}$ & $\begin{array}{l}384 \\
(91 \%)\end{array}$ & 420 & & \\
\hline
\end{tabular}


Table 5: Chorionicity and Apgar score of the first twin.

\begin{tabular}{|c|c|c|c|c|c|}
\hline $\begin{array}{l}\text { Apgar score } \\
\text { For T1 } \\
\text { Chorionicity }\end{array}$ & $\begin{array}{l}\leq 7 \\
\mathrm{n}(\%)\end{array}$ & $\begin{array}{l}>7 \\
\text { n }(\%)\end{array}$ & Total & p & OR \\
\hline $\begin{array}{l}\text { Monochorial } \\
\text { monoamniotic }\end{array}$ & $\begin{array}{l}2 \\
(20 \%)\end{array}$ & $\begin{array}{l}8 \\
(80 \%)\end{array}$ & 10 & 0.284 & - \\
\hline $\begin{array}{l}\text { Monochorial } \\
\text { biamniotic }\end{array}$ & $\begin{array}{l}19 \\
(13 \%)\end{array}$ & $\begin{array}{l}133 \\
(87 \%)\end{array}$ & 152 & & \\
\hline $\begin{array}{l}\text { Bichorial } \\
\text { biamniotic }\end{array}$ & $\begin{array}{l}24 \\
(9 \%)\end{array}$ & $\begin{array}{l}250 \\
(91 \%)\end{array}$ & 274 & & \\
\hline
\end{tabular}

We found that the Apgar score varied depending on the term of pregnancy ( $\mathrm{p}$ value $=0.006$ ). As much for $\mathrm{T} 1$ as for T2 as prematurity was a factor of poor prognosis (Table 6).

Table 6: Chorionicity and Apgar score of the second twin.

\begin{tabular}{|c|c|c|c|c|c|}
\hline $\begin{array}{l}\text { Apgar score } \\
\text { for T2 } \\
\text { Chorionicity }\end{array}$ & $\begin{array}{l}\leq 7 \\
\mathrm{n}(\%)\end{array}$ & $\begin{array}{l}>7 \\
\text { n }(\%)\end{array}$ & Total & p & OR \\
\hline $\begin{array}{l}\text { Monochorial } \\
\text { monoamniotique }\end{array}$ & $\begin{array}{l}1 \\
(10 \%)\end{array}$ & $\begin{array}{l}9 \\
(90 \%)\end{array}$ & 10 & 0.532 & - \\
\hline $\begin{array}{l}\text { Monochorial } \\
\text { biamniotique }\end{array}$ & $\begin{array}{l}12 \\
(8 \%)\end{array}$ & $\begin{array}{l}140 \\
(92 \%)\end{array}$ & 152 & & \\
\hline $\begin{array}{l}\text { Bichorial } \\
\text { biamniotique }\end{array}$ & $\begin{array}{l}31 \\
(11 \%)\end{array}$ & $\begin{array}{l}234 \\
(89 \%)\end{array}$ & 274 & & \\
\hline
\end{tabular}

We did not observe a statistically significant relationship between chorionicity and Apgar score as reported in Table 7.

Table 7: Weight of the first twin (T1) and Apgar score for $\mathbf{T} 1$.

\begin{tabular}{|llllll|}
\hline $\begin{array}{l}\text { Apgar score } \\
\text { T1 }\end{array}$ & $\leq 7$ & $>7$ & Total & p & OR \\
T1's weight & $\mathrm{n}(\%)$ & $\mathrm{n}(\%)$ & & & \\
\hline \multirow{2}{*}{$2500 \mathrm{~g}$} & 48 & 253 & 301 & 0000 & 2.68 \\
\hline \multirow{2}{*}{$2500 \mathrm{~g}$} & $(16 \%)$ & $(84 \%)$ & & & \\
\hline
\end{tabular}

There was a statistically significant relationship ( $\mathrm{p}=$ 0.002) between the Apgar score and the weight of the twins. Low birth weight was a poor prognostic factor for twins.

Table 8: Weight of the second twin (T2) and Apgar score for $\mathbf{T} 2$.

\begin{tabular}{|c|c|c|c|c|c|}
\hline $\begin{array}{l}\text { Apgar score } \\
\text { for T2 } \\
\text { T2's weight }\end{array}$ & $\begin{array}{l}\leq 7 \\
\mathrm{n}(\%)\end{array}$ & $\begin{array}{l}>7 \\
\text { n }(\%)\end{array}$ & Total & p & OR \\
\hline$<2500 \mathrm{~g}$ & $\begin{array}{l}51 \\
(15 \%)\end{array}$ & $\begin{array}{l}283 \\
(85 \%)\end{array}$ & 334 & 0.003 & 2.19 \\
\hline$\geq 2500 \mathrm{~g}$ & $\begin{array}{l}19 \\
(7 \%)\end{array}$ & $\begin{array}{l}243 \\
(93 \%)\end{array}$ & 262 & & \\
\hline
\end{tabular}

\section{DISCUSSION}

\section{Socio-demographic aspects}

The frequency of twin pregnancies in our series was $1.18 \%$ and is different from that found in the African literature; on the other hand, it is higher than that found in Europe. In fact, almost half of all twins are born in Africa. ${ }^{1,4}$ In 1999, out of about 2.8 million twins born in the world, nearly 1.1 million $(41 \%)$ were born in Africa. ${ }^{5}$ This African supremacy concerning the birth of twins is due to the fact that the birth rate remains higher, higher than the world average in this continent. The extreme ages we observed (17 and 46 years) are close to those found by Dolo in Mali (16 and 42 years) and those observed by Saadi in Morocco (19 and 44 years). ${ }^{4,6}$ Numerous studies have established that maternal age and frequency of twin pregnancies, particularly dizygotic twins, were rising, even though the number of growing follicles (those with potential candidate oocytes for ovulation) keeps decreasing., ${ }^{2,3,5}$ This concept has not been verified in our study in which the most represented age group was 25 -30 years old. Twinning was more frequent in pauciparous or multiparous women (more than half of the cases). According to Geraldine, the rate of multiple pregnancy increases with parity regardless of age. ${ }^{3}$

\section{Diagnostic aspects}

The limits of clinical examination contribute to the difficulties in diagnosing twin pregnancies during prenatal consultations and it is only during labour, and even more after the expulsion of the first twin that the diagnosis of twinning is made in our medicallyunderequipped regions. In $38 \%$ of cases, diagnosis was made in the third quarter of pregnancy less frequently in the first quarter (19\%). This is understandable because these diagnostic difficulties were found by most authors in developing countries. ${ }^{1,4,6,7}$ Conversely, in Western studies, the majority of twin diagnoses were made during pregnancy. In this regard, we quote Russel in California in the USA who observed that only $12.6 \%$ of cases in his series had not been diagnosed before entering the labour room. ${ }^{9}$ Moreover, a French study conducted by Tafforeau on the initiation of a policy of prematurity prevention noted that the average term for the diagnosis of twinning was 5.3 weeks of amenorrhea. ${ }^{2}$ Most authors agree that the precociousness of the twinning diagnosis depends on the final prognosis of a twin pregnancy., ${ }^{3,6-12}$ The aim is to set up a surveillance protocol for this high-risk pregnancy as soon as possible, as the ultimate purpose is to reduce the risk of prematurity and foetal hypotrophy, which are major contributors to perinatal morbidity and mortality. It is established that the early diagnosis of twinning requires an early systematic ultrasound scan. However, if this is feasible in developed countries with adequate equipment, it seems difficult to conceive things in the same proportions in our context, which is singled out by the 
poor state of equipment, which, even when available, is not available to large number of people.

In present study we observed that the average number of consultations was by 3.6 , i. e. more than half had their first PNC in the first quarter, but only $19 \%$ received an ultrasound scan that detected twinning. This average of 3 PNCs is also the one recorded by Saadi in Morocco. ${ }^{6}$ These results show once again the precariousness of the socio-economic conditions of our populations, leading them to a low or a delayed attendance of health facilities.

\section{Prognostic and therapeutic aspects}

Complications often disrupt the course of twin pregnancy, which ranks the latter among pregnancies at risk. ${ }^{2,3,6}$ In present study, 113 cases $(18.3 \%)$ of premature rupture of membranes, 10 cases $(1.6 \%)$ of threat of premature delivery and 7 cases $(1.1 \%)$ of placenta previa were observed. The preterm delivery rate was $25.4 \%$; lower than that observed by Dolo in Mali (41.7\%), Khrouf in Tunisia (45.92\%). ${ }^{4,9}$ Our prematurity rate is also lower than that reported in Western studies: we refer to Russel in California in the USA $(58.8 \%)$, Taforeau in France $(45 \%))^{2,9}$ In our context, despite the absence of specific management of twinning (the main reasons being lack of diagnostic resources, inadequate attendance at health facilities, low socioeconomic status), the rate of prematurity that was noted, compared to data from the literature, may be considered as acceptable for these highrisk pregnancies. On the other hand, because of the lack of equipment for breeding premature babies, the prognosis of these new-borns remains very reserved. This is amply proved in our series: the majority of early neonatal deaths were premature. Low birth weight was observed for both twins but more common in the second twin $(54.3 \%)$. This rate is significantly higher than that observed by Khrouf in Tunisia (9.84\%). ${ }^{9}$ This low birth weight, certainly due to intrauterine growth retardation (frequency is a major perinatal morbidity factor. ${ }^{11-13}$ Antenatal diagnosis is based on ultrasonic biometry, which compares data to pre-established curves that are not otherwise specific: in fact, it is conventionally assumed that the growth of twins is substantially superimposable to that of a single foetus, up to 30 weeks of amenorrhea. ${ }^{2,3}$ In our working conditions where it is not possible to carry out ultrasound examinations in all pregnant women, it is difficult to make the diagnosis of intrauterine growth retardation, since the measurement of the height of the uterus does not provide any argument although the diagnosis of twinning must first be made. In our study, it was observed that the Apgar score at the first minute was significantly similar in both foetuses. Present findings are consistent with those of Saadi et al. ${ }^{6}$ who observed no difference between the Apgar scores of the two twins at the first and fifth minutes. Nevertheless, some authors argue that the first twin is always better than the second. These contradictions are due to the methods of childbirth. ${ }^{2,12,14}$ At the end of our study we observed $306(49.4 \%)$ twin vaginal deliveries on the first twin and 286 on the second twin $(46.2 \%)$. Of the low births, $4.2 \%$ were performed with obstetric manoeuvers. This was a version per internal manoeuver in $2.8 \%$ and a large breech extraction on T2 $(2.4 \%)$ and on both twins at the same time $(0.3 \%)$. The rate of caesarean section was $50.6 \%$ for the delivery of $\mathrm{T} 1$ and $53.8 \%$ for the delivery of $\mathrm{T} 2$, a total rate of $52.2 \%$. Caesarean section on $\mathrm{T} 2$ alone accounted for $3.2 \%$ of twin deliveries.

In these cases, the delivery was performed by a midwife or by the on-duty doctor who called upon the obstetrician only in case of complications with retention of $\mathrm{T} 2$ intransverse position.

Our overall caesarean section rate is close to those found in the literature and in Western studies. Overall, caesarean rates in Western countries are significantly higher than those in developing countries. The technical platform capacity, particularly in the management of small birth weights, has a great influence on the decision to extract via caesarean section for foetal and neonatal interest.

Time series analyses had revealed an upward trend in the rate of caesarean section in the event of twin delivery. In France, the caesarean section rate stood at $50.2 \%$ in 2003 and $53.5 \%$ in $2010 .{ }^{14}$ The national caesarean section rate in 2015 was significant and estimated at $54.8 \%$ (vs. $19.9 \%$ for singleton pregnancies). However, France is among the 6 European countries with the lowest rate of twin caesarean sections. ${ }^{15}$

In present context; this is explained by the fact that $37.1 \%$ of presentations on $\mathrm{T} 1$ were breech presentations and $2.7 \%$ of transverse presentations, one quarter of the parturient women $(25.7 \%)$ were primigravidae and $10.5 \%$ among them had breech presentation for their first twin. The delivery method of twin pregnancies depending on the presentations of the twins remains controversial in the literature.

In France, most obstetricians consider twin pregnancy deliveries, if the first twin (T1) is in breech position, more at risk than a term singleton pregnancy delivery also in breech position. The delivery method that fluctuates between recommendations for systematic caesarean section when the first twin is in breech position for the American College of Obstetricians and Gynaecologists and much more conservative attitudes towards vaginal deliveries. ${ }^{15}$

A vaginal delivery in the case of breech presentation of the second twin is controversial. Some authors propose a version via external manoeuver to obtain a cephalic presentation. ${ }^{16}$ The risk of the external manoeuver version is that of transforming recommendations breech presentation into a transversal presentation which imposes a great extraction or a caesarean section. If successful, these obstetric manoeuvers can reduce the rate 
of caesarean section for extraction of the second twin, but in case of failure they compromise the foetal prognosis.

In the case of breech presentation of the first twin, most authors recommend the same indications for prophylactic caesarean section only in the case of a single pregnancy. For all the authors the indications of caesarean section are common to a single pregnancy and are bone dystocia, placenta prævia, transverse presentation for the first twin and poorly controlled pregnancy pathology. There is much more discussion, namely: scarred uterus, breech presentation, prematurity, monoamniotic monochorionic twin pregnancy due to the risks of snagging and funicular accidents. ${ }^{16}$

Conventionally, the time interval between the two births determines the prognosis for the second twin: the shorter the interval, the better the second twin's condition. ${ }^{1,2,4,5,8,9}$ The extreme delays of 2 minutes and 248 minutes that were observed are due to evacuation difficulties that our populations are experiencing. Improved medical evacuation management could help improve the foetal prognosis of twin pregnancies and more generally the pregnancy prognosis in our countries

In our study, we noted that some factors influenced foetal prognosis at birth. These factors were represented by the term of pregnancy, foetal weight, delivery method, foetal presentations and birth interval, especially for T2 prognosis. The same results were found by Ouattara in Burkina Faso and Lankoande in Senegal. ${ }^{17,18}$ These factors are represented by:

- caesarean section was almost systematic in the primigravidae, especially if in the latter, $\mathrm{T} 1$ was in breech position;

- prematurity was a factor in favour of emergency caesarean section;

- primiparous and pauciparouss women were more likely to undergo caesarean section;

- the duration of the labour lag phase and the period of time between the two births favoured the practice of emergency caesarean section;

- the failure of obstetric manoeuvers compromised the foetal prognosis and imposed the caesarean section on the second twin.

Few studies have addressed the predictive factors of emergency caesarean section in twin pregnancies; Boukerrou in France reported a rate of almost $100 \%$ of caesarean sections when the first twin was in breech presentation. $^{16}$

Maternal complications were dominated by renalvascular syndromes (26 cases \%). This finding was made by Ouattara in Burkina Faso who found a 51.82\% rate of renal-vascular syndrome. ${ }^{17}$ The delivery haemorrhage, another maternal morbidity factor that could be life threatening in our context was observed in $1.29 \%$ of cases, a rate much lower than that observed by Dolo in
Mali $(25,9 \%) .{ }^{4}$ Maternal mortality was nil in our study, which is much lower than the rates found in the African literature varying between 5 and $7 \% .^{1,4}$

\section{CONCLUSION}

Twin delivery poses varying difficulties due to the complexity of obstetrical mechanics and the frequency of dystocic presentations. Despite improved prognoses in recent years, perinatal mortality and morbidity; still high, remain a constant concern. Twin pregnancy is rarely carried to term as premature births are frequent during its course; and this, to a large extent, has an impact on the foetal prognosis. Thus, in order to receive some food for thoughts on the management of these new-borns, national surveys, following the example of Western countries, should be conducted. In this context, any maternity structure, whatever the level, should register the survival rates and sequelae rates of premature infants. All referral maternity units should develop benchmarks validated, known, shared and applied by those who are on obstetric call, if possible. Consequently, within the context of Primary Health Care, attention should include information, education and assistance activities to ensure that pregnant women receive regular and quality prenatal care within efficient and quality health structures.

\section{ACKNOWLEDGMENTS}

Authors would like to thank Dr. Nirupam, Dr. Khanna for his support during study.

Funding: No funding sources

Conflict of interest: None declared

Ethical approval: Not required

\section{REFERENCES}

1. Buanga JK. Difficulties with the management of twin pregnancy and twin birth in an African environment. Medic Black Afr. 2000;47:362-5.

2. Tafforeau J, Papiernik E, Richard A, Pons JC. Is prevention of preterm births in twin pregnancies possible? Analysis of the results of a prevention program in France (1989-1991). Europ J Obst Gynecol Reprod Biol. 1995;59:169-74.

3. Gérardin P, Boumahni B, Choker G, Carbonnier M, Gabrièle M, Heisert M, Kauffmann E, et al. Twin pregnancies in the south of the meeting hile: study cross-section over 3 years of risk factors and complications. J Gynecol Obstet Biol Reprod. 2006;35:804-12.

4. Dolo A, Dial NG, Diabate FS. About 507 pregnancies and deliveries twins in the district of Bamako. Dakar Med. 1990;35(1):25-32.

5. Gauthier H. Nations-Unies. World population prospects, the 1998 revision, New-York, 1999. Quebec Demographic Books. 2000;29(1):185:7. 
6. Saadi N. Twin pregnancy. Experience of university maternity orange trees. About 100 cases. French J Obstet Gynecol. 1998;93(6):469-74.

7. Akpabedi E. Contribution to the study for improving the prognosis of the 2nd twin at his birth. About 332 cases from January 1st to December 30th, 1982 at C.H.U.de Cocody Medical Thesis, Abidjan;1984(92).

8. Laros RK, Dattel BJ. Management of twin pregnancy: the vaginal route is still safe. Am J Obstet Gynecol. 1988;158(6):1330-8.

9. Khrouf N, Barkallah N, Ben Miled S, Ben Bechr S, Gastlih. Twin pregnancies: frequency, fetal development and perinatal mortality. J Gynecol Obstet Biol Reprod. 1983;12:619-23.

10. Michiels Y, Macel A, Jahier J, Kamp A, Feldman JP, Halfon D et al. Improvement of the foeto-neonatal prognosis of twin pregnancies. Comparison of two series of 158 pregnancies and after establishment of a therapeutic protocol. French Rev Obstet Gynecol. 1985;80(2):99-102.

11. Pons JC. Multiple pregnancies. Rev Pract. 1995;45:1742-7.

12. National College of French Obstetrician Gynecologists. Excerpt from Updates in Gynecology and Obstetrics. Recommendations for Clinical Practice: Twin pregnancies. $33^{\text {rd }}$ National Days, Paris. 2009:613-20.

13. Puech F, Vaast P, Codaccioni X, Hubert D. Twin pregnancies and multiple. Anatomical study and management. Encycl Med Chir (Paris-France), Obstetrics. 1993;5030A10:16.

14. Adam C, Allen CA, Baskettt F. Twin delivery: influence of the presentation and method of delivery on the second. Am J Obstet Gynecol. $1991 ; 165(1): 23-7$.

15. Ghassani A, Ghiduci Mc, Voglimaci M, Chollet C, Parant O. Triggering the work of twin pregnancies: comparison with monofetal pregnancies and factors associated with the risk of failure. J Gynecol Obstet Biol Reprod. 2015;(44):237-45.

16. Boukerrou M, Robillard Py, Gérardin P, Heisert M, Kauffmann E, Laffitte A et al. Presentations and modes of delivery of 371 twin pregnancies. Gynecol Obstet Fertil. 2011;39:76-80.

17. Ouattara T. Epidemiological-clinical aspects and maternal-fetal prognosis of pregnancies twins in the city of Ouagadougou Thése Med, Faculty of Health Sciences, Burkina Faso;1999(20).

18. Lankoande N. Twin pregnancy and delivery at the maternity ward of the King Baudoin health center in Dakar: epidemiological and prognostic aspects. J SAGO. 2007;8(1):10-2.

Cite this article as: Gassama $\mathrm{O}$, Mbaye M, Niass A, Boye D, Biaye B, Mbodj A et al. Epidemiological, clinical, prognostic and therapeutic aspects of twin delivery in two referral maternity units in Dakar (Senegal). Int J Reprod Contracept Obstet Gynecol 2018;7:364-70. 